\title{
Effects of Clothing in the Ming Dynasty on Modern Theatrical Costume
}

\author{
Meng Niu ${ }^{1}$, Xiangyang Bian ${ }^{1}$ *, Katharine P. Burnett ${ }^{2}$ \\ ${ }^{1}$ Fashion and Art Design College, Donghua University, Shanghai, 200050, China \\ ${ }^{2}$ Department of Art and Art History, University of California, Davis, Davis, CA95616, USA \\ *corresponding author: bianxiangyang@163.com
}

Keywords: Costume, Ming dynasty, Modern theatrical costume

\begin{abstract}
China has a long cultural history, and costumes in different dynasties are also different. Ming Dynasty is a dynasty which is closer to modern times, and its clothing has obvious influence on modern drama costume. This paper analyzes the characteristics of innovation, gorgeousness and personality and gives the concrete influences of the Ming Dynasty dress on the modern theatrical costume to provide some references for the relative researchers.
\end{abstract}

\section{Introduction}

The history of Peking Opera can be traced back to the drama of Song Zhenzong period, and the drama is a team of song and dance teams. The dance team dance, not only Dynasty relationship, and the stories are fictional, but the nature of the difference is, when cutting these skirts, only need to meet the significance and the dance would properly, not to care about dynasty song and dance play season, not the story, so the chorus even can wear the same clothes. But the different characters of the drama, not only to men and women, but also have different status, condition, is not to wear the same clothes. To the Southern Song Dynasty, although most of the Northern Song Dynasty inherited the way, but there are still relatively large changes. Because the structure of opera, is different from the Northern Song Dynasty, play with characters with more stories of singing also become more complicated, so it adds many costumes. Developed to the late Ming Dynasty, has been very developed, the rules have been almost the same as now. In the Ming Dynasty, generally can be concluded that the troupe has created a special provision based outfit, because in the Ming Dynasty, regardless of dynasties, regardless of area, regardless of the season when the three elements of the troupe outfit has made real performance. During the two hundred or three hundred years of Ming Dynasty, there were many natural changes, but by the end of the Ming Dynasty, there was little difference between the Qing Dynasty and the early Qing dynasty. Wardrobe development to the early Qing Dynasty, in general has been stereotyped, and then there is no big change in the future. The so-called stereotypes, that is, what character of the people, what kind of clothes should be worn, what the identity of the people, what kind of clothes should be worn, no major changes. As for the Zhou Qin Han Dynasty dress style system, are ignored. The traditional Beijing opera costumes are based on the Ming Dynasty costumes, and demonstrate the costumes of the dynasties in a virtual way. With a fixed form of clothing, the dress up to the three dynasties, from the Ming Dynasty to the Ming and Qing Dynasties on behalf of the people dress up.

\section{Clothing Features in the Ming Dynasty}

Innovation. The alternation of the old and the new in the Ming Dynasty and the Yuan Dynasty inevitably produced some new sparks of dress culture. At the same time, with the progress of social development in the Ming Dynasty, the costumes also have innovation and inspiration. The appearance of new forms and new elements in the Ming Dynasty reflected its creative beauty. The Ming Dynasty is said to be a dynasty, a dynasty most kinds of scarves, some is the heritage of the 
Tang and Song Dynasties style, some of the minority nationalities to spread, a variety of towel, soft towel, Ru WuShaMao, Le cap, MekasaKo. In addition, several new hat styles appeared in Ming Dynasty, and their styles were designed and designated by Zhu Yuanzhang himself. This is rare in history. The characteristics of several towel cap is not only Zhu Yuanzhang himself design, is also the towel cap containing the inspiration for Zhu Yuanzhang's play, expressed the desire to better their own dynasty regime. The Quartet also called towel, in fact which is shaped like a long cupboard, slightly trapezoidal shape worn on the head, had a bookcase described above, the towel Dynasty asked what name. He listened to the great appreciation, because there are four sides, stability, unity, political implication. Thus, the provisions of the government style, issued nationwide. The end of the Ming Dynasty, from dignitary to scholar students, all wearing it, but later changed the style, high, low, square, also slightly flat. Another creative local clothing culture in the Ming Dynasty: for thousands of years with the knots are buttons instead of the front. Buttons appeared in ancient China and were introduced into the west by china. Sixteenth Century Western widely used buttons at the same time, Chinese during the Ming Dynasty, the Ming Dynasty frequent foreign exchange, customs and Western technology, all aspects of mutual influence, mutual exchange of needed products, with the same period in western dress as the extensive use of the logical button.

Gorgeousness. The gorgeous costumes through the texture, pattern, decoration, color and other elements of the fabric texture, elegant, exquisite design, elegant red complex decoration, gorgeous color is often an important part of the dress has gorgeous beauty. It was popular in the Ming Dynasty. Satin was considered the highest quality material. But due to the influence of feudal system, mainly in the upper society of Ming emperor and powerful ministers have like to use a variety of satin fabric clothes. A silk, color silk as raw material, by weaving satin weave specific. Satin is a satin appeared in the Song Dynasty of the warp or weft, only a floating length displayed on the surface of the fabric, so the fabric surface gloss good, feel thick and smooth, soft texture, warp and weft interwoven distribution, but not connected, making technology is demanding. As mentioned before, at the beginning of the Ming Dynasty the voyages of Zheng promoted the development of silk industry, the development of commodity economy in the late of the handicraft industry also contributed to the improvement of technology, the development of the industry and the improvement of technology, make the popular Satin possible. At that time, satin was the most popular kind of silk fabrics, and even the aristocratic men's fabrics were mainly made of silk and satin. When the Ming Dynasty, in the Yangtze River to the tomb area south of the popular pouring slurry, because the closed system of pouring slurry tomb is better, the Ming Dynasty people will put Chinese medicine to protect the body in the tomb, therefore unearthed from tomb relics in pouring slurry has been excavated, remained intact, in a large tomb unearthed in the tomb, coffin status, identity, or common Satin dress. In the early years of Ming Dynasty, they advocated simplicity and frugality, and had a strict system. People dress in accordance with the law. And color as an important component of clothing, of course, is no exception, Ming Dynasty dress colors according to different grades have different provisions. With the seeds of capitalism in the late Ming Dynasty, people's ideological liberation to make people break through the feudal shackles, dress more gorgeous colorful, staining and the consumption psychology, developed to complement each other, the Ming Dynasty costumes colorful scene. Now the costumes gorgeous, heavy decoration, from material to color to the design of the pursuit of gorgeous.

Personality. Dress is an aesthetic function, the strict dress hierarchy in the Ming Dynasty contains Zhu Yuanzhang's political purpose and national consciousness, but it cannot restrain people's pursuit of individuality and aesthetics for a long time. In the middle and late Ming Dynasty, dress became more and more personalized, and people wanted to break through the shackles of feudalism. Now, the dress was not only serious, but also appeared in many other kinds of clothing. In the late Ming Dynasty, people dress from the style to the fabric color patterns are breaking through the level limit, and even the emperor special reward, bullfight and flying by folk with Ying clothing. After the restoration, fish patterns are still. There are plenty of people, although again banned, but still. In the late Ming Dynasty, people tried to follow the fashion, no longer satisfied with the replacement of clothing styles and the use of materials, but did everything possible to seek new and strange stimuli or to publicize their individuality. It is not surprising that the clothing materials of the Ming Dynasty are 
rich and colorful, and the handicraft industry in Ming Dynasty is well developed, so the fabrics and patterns are developed. Overseas trade makes the American fabric spread, can enrich people's clothing fabrics. Paddy clothing in the middle and late Ming Dynasty can be another breakthrough in traditional costumes. Paddy clothing is different with fabric stitching and fabric, different colors, sizes, shapes, well-proportioned sewn together, usually worn by women, because much like a piece of cloth between the southern paddy field, so called "paddy clothing". The Tang Dynasty clothing in the open paddy field had appeared in the middle and late Ming Dynasty, but the popular and widely accepted women. In the feudal society, which emphasizes the dress system, the whole dress has legal requirements, and the appearance of Mizuta I is a great breakthrough. Its emergence needs special political and ideological factors to pave the way. Therefore, this is not a traditional part, but an alternative to the dress system in the Ming dynasty. Mizuta I's artistic effects are not repetitive. The paddy clothes made by different people have their own unique splicing effect and style, and they are very beautiful.

\section{Effects of Clothing in the Ming Dynasty on Modern Theatrical Costume}

Python Clothing. The python costume in Ming Dynasty was mainly the emperor's given service to the meritorious ministers". Python and the dragon is very similar, but to distinguish with the emperor robes of four claw dragon image, python. Peking Opera in the python, mainly the emperor, king, princes, and the dress style for the neck and right side ", Wang Dajin, the pendulum can be found from the Ming Dynasty clothing prototype python. Only in the Peking Opera in the process of development, the color and the pattern of adding other elements, for example, characteristics of clothing hem of the python water pattern tends to the Qing Dynasty, the use of color in shaping the character, the Yellow Emperor, Wang Jue said, for white, the prince said solemnly, for the red black upright, for the Marquis said rude, or a rude man wearing a green table fortitude, honest people to wear. In the drama, the play also embroidered robe worn by emperor, according to different kinds of roles, can be divided into the following kinds: red is the color of the most precious: Python clothing, according to the rules of the Grand Marshal shall wear this, but sometimes also have access to. Generally, wear red python, are loyal, such as the bridegroom is fixed in red python. The green Python: color, highly valued according to the rules, is the superior general wear, roughly the martial arts wear the loyal, loyal all red, you must wear this, such as Guan Yu, Jiang Wei and so on. Yellow: Yellow python for the emperor or wear jade behoove, head slightly the whole troupe, and bright yellow and apricot branch. Wang Jue is wearing a yellow, such as apricot, it will wear yellow color or fragrance. White Python: This Python in clothing is also quite serious, wearing this, roughly divided into two kinds: one is the old. Zhao Gao, in the drama are bad. In addition, there are sweet color pink python, python, python, python, crimson light green blue purple python, Python and so on. Male and female python embroidered must come first, male, female Python embroidered in Python, also embroidered pattern size, male pythons are slightly shorter, that women must wear a skirt. There is a woman wearing a python must shoulder, man only collar, is divided into a variety of colors, with roughly the same male Python color standard.

Pleats. Fold is usually take the clothes, and now is because of Taoist Tao Yi, also known as surplices. Men's pleats originated in the Ming Dynasty men's casual clothes -- oblique collar and large sleeves, which were ancient Chinese traditional clothes and patterns. They were used by civilians and scholars in the Tang and song dynasties. While women's fold is developed in the Ming Dynasty small collar coat Doujin narrow sleeve based on. The woman with a short coat, the skirt, a big sleeve or narrow sleeve Bei son, exposed only small collar. This is a small collar is late in the history of the Ming Dynasty and China, it is widely used, as is the embodiment of the ideological shackles in neo-Confucianism women dress on. To the Qing Dynasty, in the strict provisions, Han women to Ming Dynasty followed the use of so-called collar jacket and Bei Han dress. So, the Peking opera originated in the Qing Dynasty, opposite the square collar coat of Bei, combines the characteristics of the two, will be made one create underwear coat, opera on the stage of small collar shirt - women's fold, also colored. Traditional opera costumes come from life, but different from life, compared with life clothing, it is more decorative, but also pay more attention to the coordination of the whole body. 
To give the audience to enjoy the beauty of clothing with beautiful ornaments, opera, such as bead flower, floccules, silk sash, pile tail. On the stage in the purple crown put two long hard tail, increased the number of theatrical opportunities for actors to live color coke. This is nothing in life. Some types of traditional opera costumes also come from life, different from life. If the general characters such as civilians, wear clothes, is called folds from fold since the Qin and Han dynasties. In real life, both men and women in the Ming Dynasty wore pleats.

Complementor. Chinese complementor refers to the ancient robes trimmed with diamond pattern, mainly in the Ming and Qing Dynasties two generation robes, square silk fabric, embroidered with different patterns of birds and animals, and to different levels and level on behalf of officials. So, a symbol of identity complements is that time, as now the medal of the same grade mark with. Sub area is not large, from which they can better see the center position of the inheritance of the traditional culture in Chinese complementor conspicuous in the clothing in the chest and back. My heart to let complementor surrounded, officials always remember Imperial Grand, dedicated to the country for you to. The back and chest complementor echoed, and can let people know that the back of his office, and in person to bear the straightens out the official authority. Modern clothing is not influenced by religion, politics and culture. It starts from the aesthetic and makes the use of patterns freer. Complementor are usually scattered robes or symmetrical circular patterns, patterns of requirements integrity, such as the emperor court robes, left shoulder dragon is symmetrical layout. In modern times, many clothing absorb the essence of western style cutting, and the circular pattern still retains the scattered layout, but it has become no longer complete. This incomplete pattern can endow the modern costume with a sense of liveliness. Chinese many local brands, such as fishing, Providence, will this feature work well in modern clothing. He returned to the formal dress, because of the importance of Chinese etiquette, dress has special requirements, at the same time, the dress has a unique symbolic meaning, contains many aspects of culture, as mentioned above, on different occasions to wear different costumes, so the Ming Dynasty costumes must display the costumes and cultural characteristics. Opera has the function of reproducing real life, so we can explore the cultural information from the costumes. In the three hundred years of the Ming Dynasty opera performance practice in art has constantly improved, based on the previous generation of aesthetic principles, accumulated rich practical experience and skills, mainly reflected in the figures of the attention and the pursuit of the stage effect on character modeling is mainly reflected in the focus on Facebook and this paper focuses on clothing, clothing culture embodied in opera.

\section{Conclusion}

Chinese modern theatrical costume is the recreation of ancient costume and art. It was mainly made up of the Ming Dynasty costumes and blended with the styles of dress from the Tang Dynasty to the Qing dynasty. Through the analysis of the Ming Dynasty opera stage art in the Ming Dynasty costumes, stage art clothing has made great progress based on previous studies, and explores the new way for stage clothing art in the future.

\section{Acknowledgements}

This research was supported by the Shanghai Summit Discipline in Design project.

\section{References}

[1] Wang Yue. The UsageofYunjian in Chinese Clothing in the Ming Dynasty [J]. Journal ofGansuLianhe University (SocialSciences), 2013, 29(3): 125-128.

[2] Zhang Jingqiong, Hong Anna. Improvement of clothing silhouette in Ming dynasty and its local breakthrough for etiquette [J]. Journal of Silk, 2016, 53(7): 62-67.

[3] Yang Qiuhong. On the Drama of"Robe and Wat"-Withthe Evolution oftheArmy Color andSolitary Color Clothes in Dramas of Yuan and Ming Dynasties [J].Journal of University of Science and Technology Beijing(SocialSciences Edition), 2016, 32(2): 100-108. 
[4] Hua Junping. Applicationof Ming and Qing dynastiesBuzi in the modern clothing [J]. Melliand China, 2015(10): 66-70. 